\title{
Lymph node metastasis and preoperative diagnosis of depth of invasion in early gastric cancer
}

\author{
Yasuyuki Seto ${ }^{1}$, Shouji Shimoyama ${ }^{1}$, Jouji Kitayama ${ }^{2}$, Kenichi Mafune ${ }^{1}$, Michio Kaminishi ${ }^{1}$, Takashi Aikou ${ }^{3}$, \\ Kuniyoshi Arai ${ }^{4}$, Keilchiro Ohta ${ }^{5}$, Atsushi Nashimoto ${ }^{6}$, Ichiro Honda ${ }^{7}$, Hisakazu Yamagishi ${ }^{8}$, \\ and Yoshitaka Yamamura ${ }^{9}$ \\ ${ }^{1}$ Department of Gastrointestinal Surgery, Graduate School of Medicine, The University of Tokyo, Tokyo, Japan \\ ${ }^{2}$ Department of Surgical Oncology, Graduate School of Medicine, The University of Tokyo, Tokyo, Japan \\ ${ }^{3}$ First Department of Surgery, Kagoshima University School of Medicine, Kagoshima, Japan \\ ${ }^{4}$ Department of Surgery, Tokyo Komagome Metropolitan Hospital, Tokyo, Japan \\ ${ }^{5}$ Department of Surgery, Cancer Institute Hospital, Tokyo, Japan \\ ${ }^{6}$ Division of Surgery, Niigata Cancer Center Hospital, Niigata, Japan \\ ${ }^{7}$ Department of Surgery, Chiba Cancer Center, Chiba, Japan \\ ${ }^{8}$ Department of Gastroenterological Surgery, Kyoto Prefectural University of Medicine, Kyoto, Japan \\ ${ }^{9}$ Department of Surgery, Aichi Cancer Center Hospital, Nagoya, Japan
}

\begin{abstract}
Background. No reports have, to date, focused on the relationship between preoperative determination of the depth of invasion and lymph node metastasis. The present study, under the leadership of the Japanese Gastric Cancer Association, was designed to form a basis for decision making in limited treatment for early gastric cancer (EGC).

Methods. From eight major hospitals in Japan, 2672 gastric cancers whose preoperative depth of invasion was mucosal(M-cancer), and 6209 EGCs, consisting of 3584 mucosal(m-) and 2625 submucosal(sm-) cancers, were collected by questionnaire. All registered patients underwent gastrectomy with D1 or more extensive lymphadenectomy between 1985 and 1998.

Results. The accuracy of preoperative diagnosis of depth of invasion of M-cancers was $80.2 \%$ (2144/2672). However, of the total of 2432 M-cancers in which no nodal involvement was observed intraoperatively (N0), histological examination of the resected specimens confirmed that lymph node metastasis was absent in $2353(96.8 \%)$. The frequencies of lymph node metastasis in early gastric, m-, and sm-cancers were $8.9 \%$, $2.5 \%$, and $17.6 \%$, respectively. Node involvement was associated with a higher frequency of undifferentiated than differentiated histology, as well as with greater tumor size. The incidences of lymph node metastasis in m-cancers with a diameter of less than $4 \mathrm{~cm}$, and in sm-cancers with a diameter below $1 \mathrm{~cm}$ were $1.3 \%(37 / 2837)$ and $4.9 \%$ (4/82), respectively. These metastases rarely extended beyond the first tier. Conclusion. N0 and M-cancers, m-cancers less than $4 \mathrm{~cm}$ in diameter, and sm-cancers no larger than $1 \mathrm{~cm}$ in diameter may be appropriate indications for limited surgery.
\end{abstract}

Offprint requests to: Y. Seto, Department of Surgery, Nakadori General Hospital, 3-15 Minamidori Misonomachi, Akita, 010-8577, Japan

Received: January 23, 2001 / Accepted: March 15, 2001
Key words Early gastric cancer $\cdot$ Lymph node metastasis . Preoperative diagnosis

\section{Introduction}

Early gastric cancer (EGC), defined as a tumor with invasion confined to the mucosa or submucosa, is now recognized as a curable malignancy [1-30]. The reported frequency of lymph node metastasis in EGC varies from $5.7 \%$ to $29 \%$ [1-26,31-38]. Most studies have reported that the presence of lymph node metastasis decreases the survival rate of EGC patients [7-30]. The different frequencies oßf nodal involvement in mucosal versus submucosal cancer are well known. The reported frequency of lymph node metastasis in submucosal cancer varies from $9.7 \%$ to $24.3 \%$ [4-18,28-37,3941], whereas that in mucosal cancer is low $(0 \%-6.4 \%)$ [4-18,31-37,42]. Recently, different treatment methods have been employed for mucosal and submucosal cancers. For the mucosal cancers, limited treatments, e.g., endoscopic mucosal resection $[32-35,42]$ or local resection, with [43] or without $[16,17,35,36,44]$ lymphadenectomy, are indicated. Therefore, preoperative diagnosis of depth of invasion is very important for selecting the most appropriate treatment procedures. However, few studies have focused on the relationship between the preoperative diagnosis of depth of invasion and lymph node metastasis.

This study, carried out under the auspices of the Japanese Gastric Cancer Association, was designed to determine the accuracy of preoperative diagnosis of the depth of invasion and the frequency of lymph node metastasis in EGC. The present results will form a basis 
for decision making in regard to limited treatment for EGC.

\section{Patients and methods}

Data on patients with single EGC were collected by questionnaire from eight major hospitals in Japan. Items on the questionnaire were as follows: preoperative diagnosis of depth of invasion of the tumor, intra-operative findings of nodal involvement, and histological examinations of the resected specimens. All patients underwent gastrectomy with D1 or more extensive lymphadenectomy between 1985 and 1998. The methods of determining depth of invasion preoperatively varied among institutes. Endoscopy, endoscopic ultrasonography, and barium gastrography were used routinely. Tumor size in this study was determined histologically, using the resected specimen, and the histology was classified as differentiated and undifferentiated types. Extent of lymph node metastasis ( $n$ number) and classification of macroscopic shape were based on the General rules for the gastric cancer study (12th edition). No attempt was made herein to assess whether ulceration was present in tumorous lesions. Lymph node metastasis was diagnosed as positive intraoperatively, by the presence of hard and swollen nodes, and/or by frozen section analysis.

In the present study, tumors with invasion histologically confined to the mucosa or the submucosa were defined as $\mathrm{m}$-cancer and sm-cancer, respectively. Tumors in which invasion was preoperatively considered to be confined to the mucosa were diagnosed as $\mathrm{M}$ cancers. Statistical analyses were performed using the $\chi^{2}$ test. The accepted level of significance was $P<0.05$.

\section{Results}

Of a total of 2672 M-cancers, 2144 were m-cancers histologically, i.e., the accuracy of preoperative diagnosis of depth of invasion was $80.2 \%$ for M-cancers, and accuracies varied from $67 \%$ to $89.9 \%$ across the contributing institutes. The frequencies of sm and advanced cancer in the M-cancers were $17.5 \%$ and $2.2 \%$, respectively. Of the total of 2432 M-cancers with intraoperative findings indicating the absence of nodal involvement (N0), histological examination of the resected specimens confirmed $2353(96.8 \%)$ to be free of lymph node metastasis. The ratios were similar (95\%-98\%) across participating hospitals. The $\mathrm{n} 1$ and $\mathrm{n} 2$ metastases were histologically observed in $2.7 \%(66 / 2432)$ and $0.5 \%$ (13/2432), respectively, of N0 and M-cancers. None of the M-cancers had $\mathrm{n} 3$ metastasis. The accuracy of macroscopic findings of $\mathrm{N} 0$ in $\mathrm{M}$-cancer, according to the
Table 1. Accuracy of macroscopic findings of NO lymph node metastasis in M-cancer

\begin{tabular}{lcccc}
\hline & \multicolumn{1}{c}{ Correct } & & \multicolumn{2}{c}{ Incorrect } \\
\cline { 2 - 2 } Histology & $\mathrm{n} 0$ & & $\mathrm{n} 1$ & $\mathrm{n} 2$ \\
\hline $\begin{array}{c}\text { Differentiated } \\
(n=1606)\end{array}$ & $1578(98.3 \%) *$ & & $24(1.5 \%)$ & $4(0.2 \%)$ \\
$\begin{array}{c}\text { Undifferentiated } \\
(n=825)\end{array}$ & $774(93.8 \%)$ & & $42(5.1 \%)$ & $9(1.1 \%)$ \\
$* P<0.01$ vs undifferentiated & & & \\
\hline $\begin{array}{l}* \\
*\end{array}$ & & &
\end{tabular}

Table 2. Incidence of lymph node metastasis according to histology

\begin{tabular}{lcc}
\hline Depth $^{\mathrm{a}}$ & Differentiated & Undifferentiated \\
\hline $\mathrm{m}$ & $25 / 2273(1.1 \%)^{*}$ & $63 / 1311(4.8 \%)$ \\
$\mathrm{sm}$ & $52 / 1616(3.2 \%)^{*}$ & $211 / 1009(20.9 \%)$ \\
\hline
\end{tabular}

$* P<0.01$ vs undifferentiated

aSee text for definitions of " $\mathrm{m}$ " and "sm"

Table 3. Incidence of lymph node metastasis according to tumor size in $\mathrm{m}$-cancer

\begin{tabular}{lcc}
\hline Tumor size $(\mathrm{cm})$ & Differentiated & Undifferentiated \\
\hline$\leqq 0.9$ & $0 / 268(0 \%)$ & $1 / 69(1.4 \%)$ \\
$1-1.9$ & $2 / 699(0.3 \%)$ & $5 / 279(1.8 \%)$ \\
$2.0-3.9$ & $11 / 950(1.2 \%)$ & $18 / 572(3.1 \%)$ \\
$\geqq 4.0$ & $12 / 356(3.4 \%)$ & $39 / 391(10.0 \%)$
\end{tabular}

histological type of the tumor, is shown in Table 1. Accurate intraoperative evaluations of nodal involvement were significantly fewer in cases with undifferentiated than in those with differentiated tumors.

In total, 6209 EGCs were collected: $3584 \mathrm{~m}$-cancers and $2625 \mathrm{sm}$-cancers. The frequency of lymph node metastasis in the present series of EGCs was 8.9\% (551/ $6209)$. Nodal involvement was observed in $88(2.5 \%)$ of the $3584 \mathrm{~m}$-cancers and in $463(17.6 \%)$ of the $2625 \mathrm{sm}$ cancers, a significant difference $(P<0.01)$. The incidence of lymph node metastasis according to tumor histology is shown in Table 2. The frequency of nodal involvement was significantly higher in cancers with undifferentiated than with differentiated histology, for both $\mathrm{m}$ - and sm-cancers. The incidences of lymph node metastasis, according to tumor size, for m-cancer and sm-cancer, are presented in Tables 3 and 4, respectively. Five $\mathrm{m}$-cancers with diameters less than $4 \mathrm{~cm}(0.2 \%$; $5 / 2837$ ) had $n 2$ lymph node metastasis. The features of these tumors are summarized in Table 5. Ten elevated m-cancers had lymph node metastasis (Table 6). All ten cancers were histologically differentiated. Nodal involvement was observed in four sm-cancers with diameters less than $1 \mathrm{~cm}(4.9 \%$; 4/82) (Table 7). 


\section{Discussion}

To date, a number of studies have focused on EGC. However, these earlier reports were, with one exception [31], based on the outcomes of fewer than 1500 subjects (80-1475 cases) [1-30,32-42]. Furthermore, there have been no studies on the relationship between preoperative determination of depth of invasion and lymph node metastasis. The present study is the first, to our knowledge, to address this issue in a patient population exceeding 2000.

The reported accuracy of preoperative depth diagnosis of M-cancer varies from $69.2 \%$ to $92.2 \%$ [45-53], which is consistent with the range in the present results $(67 \%-89.9 \%)$. The presence of ulcer fibrosis in the lesion is well known to hamper diagnosis [51-54], but we did not collect data on ulceration in this study. A discrepancy between macroscopic (intraoperative) and histological (postoperative) diagnosis of node involvement has been reported [55-59]. However, in this study, the accuracy of macroscopic findings on node involvement in N0 and M-cancers was quite high (95\%-98\%), and this was consistent across institutes. Of the $2432 \mathrm{NO}$ and $\mathrm{M}$-cancers, there were none with $\mathrm{n} 3$ metastasis, and $\mathrm{n} 2$ metastasis was quite rare $(0.5 \%)$. Therefore, limited surgery may be appropriate for N0 and M-cancers. The present study demonstrated intraoperative evaluations of nodal involvement to be less reliable in undifferentiated than in differentiated tumors, a finding that is consistent with our previous report [59]. Frozen section analysis of nodes sampled during limited surgery is routinely used at our institute.

The frequencies of lymph node metastasis in EGC $(8.9 \%)$, m-cancer $(2.5 \%)$, and sm-cancer $(17.6 \%)$ in the present series confirmed the results of earlier reports. Many previous studies [10-17,29,30,32-34,39-41], al-

Table 4. Incidence of lymph node metastasis according to tumor size in sm-cancer

\begin{tabular}{lrr}
\hline Tumor size $(\mathrm{cm})$ & Differentiated & Undifferentiated \\
\hline$\leqq 0.9$ & $2 / 65(3.1 \%)$ & $2 / 17(11.8 \%)$ \\
$1-1.9$ & $36 / 349(10.3 \%)$ & $25 / 193(13.0 \%)$ \\
2.0 & $214 / 1202(21.7 \%)$ & $184 / 799(23.0 \%)$ \\
\hline
\end{tabular}

though not all $[5,18,35,42]$, showed tumor histology to have no correlation with node involvement. However, in the present study, based on a nationwide investigation, in both $\mathrm{m}$ - and sm-cancers, the incidence of lymph node metastasis was significantly higher in undifferentiated than in differentiated tumors. These results are important for determining the optimal treatments for EGCs.

The increase in node involvement with tumor size (irrespective of histology and cancer depth), ascertained in the present study, is consistent with the findings of previous reports [2,5,11-19,32-40,42]. Endoscopic mucosal resection is clearly indicated for differentiated $\mathrm{m}$-cancers less than $1 \mathrm{~cm}$ in diameter, given the absence of nodal involvement in these tumors. In mcancers with a diameter of less than $4 \mathrm{~cm}$, the incidence of node involvement was observed to be low. Therefore, limited surgery can be employed as a curative treatment for such tumors. At our institute, local resection with

Table 6. Elevated m-cancers with lymph node metastasis

\begin{tabular}{lllc}
\hline $\begin{array}{l}\text { Tumor } \\
\text { size }(\mathrm{cm})\end{array}$ & $\begin{array}{c}\text { Tumor } \\
\text { location }\end{array}$ & $\begin{array}{c}\text { Macroscopic } \\
\text { shape }\end{array}$ & $\begin{array}{c}\text { Extent of } \\
\text { metastasis }\end{array}$ \\
\hline $1-1.9$ & Lower & IIa + IIc & $\mathrm{n} 2$ \\
$1-1.9$ & Lower & IIa + IIc & $\mathrm{n} 2$ \\
$2-2.9$ & Lower & I & $\mathrm{n} 1$ \\
$3-3.9$ & Lower & I + IIb & $\mathrm{n} 1$ \\
$3-3.9$ & Lower & IIa & $\mathrm{n} 1$ \\
$4-4.9$ & Lower & IIa + IIc & $\mathrm{n} 1$ \\
$4-4.9$ & Lower & IIa + IIc & $\mathrm{n} 1$ \\
$\geqq 5$ & Middle & I & $\mathrm{n} 1$ \\
$\geqq 5$ & Middle & I + IIa & $\mathrm{n} 1$ \\
$\geqq 5$ & Lower & IIa + IIc & $\mathrm{n} 1$ \\
\hline
\end{tabular}

Table 7. Four sm-cancers with a diameter less than $1 \mathrm{~cm}$ and nodal involvement

\begin{tabular}{|c|c|c|c|}
\hline $\begin{array}{l}\text { Tumor } \\
\text { location }\end{array}$ & Histology & $\begin{array}{c}\text { Macroscopic } \\
\text { shape }\end{array}$ & $\begin{array}{c}\text { Metastatic } \\
\text { site }\end{array}$ \\
\hline Upper & Undifferentiated & $\mathrm{IIc}+\mathrm{III}$ & No. $4 \mathrm{sb}$ \\
\hline Upper & Differentiation & IIc & No. 3 \\
\hline Middle & Undifferentiation & $\mathrm{IIc}+\mathrm{III}$ & No. $4 \mathrm{sb}$ \\
\hline Lower & Differentiated & $\mathrm{I}+\mathrm{IIc}$ & No. 6 \\
\hline
\end{tabular}

Table 5. Five m-cancers with a diameter less than $4 \mathrm{~cm}$ and $\mathrm{n} 2$ metastasis

\begin{tabular}{|c|c|c|c|c|}
\hline $\begin{array}{l}\text { Tumor } \\
\text { size }(\mathrm{cm})\end{array}$ & $\begin{array}{l}\text { Tumor } \\
\text { location }\end{array}$ & Histology & $\begin{array}{c}\text { Macroscopic } \\
\text { shape }^{\mathrm{a}}\end{array}$ & $\begin{array}{c}\text { Metastatic } \\
\text { site }^{a}\end{array}$ \\
\hline $1-1.9$ & Lower & Differentiated & $\mathrm{IIa}+\mathrm{IIc}$ & No. 1 \\
\hline $1-1.9$ & Lower & Differentiated & $\mathrm{IIa}+\mathrm{IIc}$ & No. 8a \\
\hline $2-2.9$ & Middle & Undifferentiated & IIc & No. 7 \\
\hline $3-3.9$ & Lower & Differentiated & IIc & No. 7 \\
\hline $3-3.9$ & Middle & Undifferentiated & IIc & Nos. 3,7 \\
\hline
\end{tabular}

${ }^{a}$ According to the General rules for the gastric cancer study (12th edition) 
regional lymphadenectomy is indicated for m-cancer less than $4 \mathrm{~cm}$ in diameter [43]. Lymph node metastasis to the second tier (n2) was very rare $(0.2 \%)$ in $\mathrm{m}$ cancers less than $4 \mathrm{~cm}$ in diameter. However, careful consideration is needed in deciding whether limited surgery is appropriate for IIa + IIc type m-cancer, because node no. 8a, which was positive in one of our patients (Table 5), is not usually dissected during these procedures. Elevated m-cancers were reported to have very few $[32,35,42]$ or no $[7,18,37]$ lymph node metastases. In the present series, lymph node metastasis was observed with type I and type IIa tumors with diameters exceeding $2 \mathrm{~cm}$ and $3 \mathrm{~cm}$, respectively (Table 6). Several studies have shown a high frequency of nodal involvement in macroscopically combined type, e.g., IIa + IIc, as compared with the other tumor types $[1,17]$. The present results also showed m-cancers with IIa + IIc morphology to be likely to have lymph node metastasis, even when they were less than $2 \mathrm{~cm}$ in diameter (Table 6).

A previous study reported that nodal metastasis was absent in sm-cancers less than $1 \mathrm{~cm}$ in diameter [34]. Our results indicate the presence of lymph node metastasis in such tumors (Table 7), which is consistent with the findings of other studies [35,40]. However, the extent of lymph node metastasis observed in the present series was consistently within the first tier (n1). Therefore, limited surgery may be appropriate for sm-cancers less than $1 \mathrm{~cm}$ in diameter.

Limited surgery, in particular, local resection, should be employed for EGC without lymph node metastasis, whereas additional extended lymphadenectomy is necessary when nodal involvement is observed intraoperatively or on histological examination of the resected specimen. However, most patients who have a diagnosis of M-cancer and N0 can benefit from local resection.

\section{References}

1. Green PH, O'Toole KM, Weinberg LM, Goldfarb JP. Early gastric cancer. Gastroenterology 1981;81:247-56.

2. Yoon CM, Rew JS, Bom HS, Choi SK, Yang DH, Cho JK. Early gastric cancer in Korea. Korean J Intern Med 1989;4:6573.

3. Moreaux J, Bougaran J. Early gastric cancer. A 25-year surgical experience. Ann Surg 1993;217:347-55.

4. Itoh H, Oohata Y, Nakamura K, Nagata T, Mibu R, Nakayama F. Complete 10-year postgastrectomy follow-up of early gastric cancer. Am J Surg 1989;158:14-6.

5. Eriguchi M, Miyamoto Y, Fujii Y, Takeda Y, Osada I, Hagihara $\mathrm{T}$, et al. Regional lymph node metastasis of early gastric cancer. Eur J Surg 1991;157:197-200.

6. Lin JT, Wu MS, Wang JT, Shun CT, Chen CJ, Wang TH. Clinicopathologic study of 208 patients with early gastric cancer in Taiwan: a comparison between Eastern and Western countries. J Gastroenterol Hepatol 1994;9:344-9.

7. Kitaoka H, Yoshikawa K, Hirota T, Itabashi M. Surgical treatment of early gastric cancer. Jpn J Clin Oncol 1984;14:28393.
8. Pinto E, Roviello F, de Stefano A, Vindigni C. Early gastric cancer: report on 142 patients observed over 13 years. Jpn J Clin Oncol 1994;24:12-9.

9. Isozaki H, Tanaka N, Okajima K. General and specific prognostic factors of early gastric carcinoma treated with curative surgery. Hepatogastroenterology 1999;46:1800-8.

10. Kim JP, Hur YS, Yang HK. Lymph node metastasis as a significant prognostic factor in early gastric cancer: analysis of 1136 early gastric cancers. Ann Surg Oncol 1995;2:308-13.

11. Habu H, Takeshita K, Sunagawa M, Endo M. Lymph node metastasis in early gastric cancer. Int Surg 1986;71:244-7.

12. Endo M, Habu H. Clinical studies of early gastric cancer. Hepatogastroenterology 1990;37:408-10.

13. Maehara Y, Orita H, Okuyama T, Moriguchi S, Tsujitani S, Korenaga D, et al. Predictors of lymph node metastasis in early gastric cancer. Br J Surg 1992;79:245-7.

14. Seto Y, Nagawa H, Muto T. Impact of lymph node metastasis on survival with early gastric cancer. World J Surg 1997;21:186-90.

15. Hanazaki K, Wakabayashi M, Sodeyama H, Makiuchi A, Igarashi J, Yokoyama S, et al. Surgical outcomes in early gastric cancer with lymph node metastasis. Hepatogastroenterology 1997;44: 907-11.

16. Kitamura K, Yamaguchi T, Taniguchi H, Hagiwara A, Sawai K, Takahashi T. Analysis of lymph node metastasis in early gastric cancer: rationale of limited surgery. J Surg Oncol 1997;64:42-7.

17. Yokota T, Saito T, Teshima S, Kikuchi S, Kunii Y, Yamauchi H. Lymph node metastasis in early gastric cancer: how can surgeons perform limited surgery? Int Surg 1998;83:287-90.

18. Tsujitani S, Oka S, Saito H, Kondo A, Ikeguchi M, Maeta M, et al. Less invasive surgery for early gastric cancer based on the low probability of lymph node metastasis. Surgery 1999;125:148-54.

19. Hochwald SN, Brennan MF, Klimstra DS, Kim S, Karpeh MS. Is lymphadenectomy necessary for early gastric cancer? Ann Surg Oncol 1999;6:664-70.

20. Lawrence M, Shiu MH. Early gastric cancer. Twenty-eight-year experience. Ann Surg 1991;213:327-34.

21. Lehnert T, Sternberg SS, Sprossmann M, DeCosse JJ. Early gastric cancer. Am J Surg 1989;157:202-7.

22. Inoue K, Tobe T, Kan N, Nio Y, Sakai M, Takeuchi E, et al. Problems in the definition and treatment of early gastric cancer. Br J Surg 1991;78:818-21.

23. Guadagni S, Reed PI, Johnston BJ, De Bernardinis G, Catarci M, Valenti M, et al. Early gastric cancer: follow-up after gastrectomy in 159 patients. Br J Surg 1993;80:325-8.

24. Baba H, Maehara $Y$, Takeuchi $H$, Inutsuka S, Okuyama $T$, Adachi Y, et al. Effect of lymph node dissection on the prognosis in patients with node-negative early gastric cancer. Surgery 1994;117:165-9.

25. Pacelli F, Doglietto GB, Alfieri S, Carriero C, Malerba M, Crucitti $\mathrm{PF}$, et al. Survival in early gastric cancer: multivariate analysis on 72 consecutive cases. Hepatogastroenterology 1999;46:1223-8.

26. Tuech JJ, Cervi C, Pessaux P, Villapadierna F, Bergamaschi R, Ronceray J, et al. Early gastric cancer: univariate and multivariate analysis for survival. Hepatogastroenterology 1999;46:3276-80.

27. Sano T, Sasako M, Kinoshita T, Maruyama K. Recurrence of early gastric cancer. Cancer 1993;72:3174-8.

28. Ichiyoshi Y, Toda T, Minamisono Y, Nagasaki S, Yakeishi Y, Sugimachi K. Recurrence in early gastric cancer. Surgery 1990;107:489-95.

29. Kurihara N, Kubota T, Otani Y, Ohgami M, Kumai K, Sugiura H, et al. Lymph node metastasis of early gastric cancer with submucosal invasion. Br J Surg 1998;85:835-9.

30. Kubota H, Tabara H, Kotoh T, Kumar DD, Monden N, Watanabe R, et al. Prognostic factors and rational approach in the treatment of submucosal cancer of the stomach. J Surg Res 1998;80:304-8.

31. Fukutomi H, Sakita T. Analysis of early gastric cancer cases collected from major hospitals and institutes in Japan. Jpn J Clin Oncol 1984;14:169-79. 
32. Sano T, Kobori O, Muto T. Lymph node metastasis from early gastric cancer: endoscopic resection of tumour. Br J Surg 1992; 79:241-4.

33. Torii A, Sakai M, Inoue K, Yamabe H, Okuma M. A clinicopathological analysis of early gastric cancer: retrospective study with special reference to lymph node metastasis. Cancer Detect Prev 1994;18:437-41.

34. Nakamura K, Morisaki T, Sugitani A, Ogawa T, Uchiyama A, Kinukawa N, et al. An early gastric carcinoma treatment strategy based on analysis of lymph node metastasis. Cancer 1999;85:15005.

35. Maekawa S, Takeo S, Ikejiri K, Anai H, Saku M. Clinicopathological features of lymph node metastasis in early gastric cancer. Int Surg 1995;80:200-3.

36. Sowa M, Kato Y, Nishimura M, Kubo T, Maekawa H, Umeyama K. Surgical approach to early gastric cancer with lymph node metastasis. World J Surg 1989;13:630-5.

37. Baba H, Maehara Y, Okuyama T, Orita H, Anai H, Akazawa K, et al. Lymph node metastasis and macroscopic features in early gastric cancer. Hepatogastroenterology 1994;41:380-3.

38. Takeshita K, Saeki I, Tani M, Honda T, Saito N, Endo M. Rational lymphadenectomy for early gastric cancer with submucosal invasion: a clinicopathological study. Surg Today 1998;28:580-6.

39. Ichikura $\mathrm{T}$, Uefuji $\mathrm{K}$, Tomimatsu S, Okusa $\mathrm{Y}$, Yahara $\mathrm{T}$, Tamakuma S. Surgical strategy for patients with gastric carcinoma with submucosal invasion. Cancer 1995;76:935-40.

40. Ishigami S, Hokita S, Natsugoe S, Tokushige M, Saihara T, Iwashige $\mathrm{H}$, et al. Carcinomatous infiltration into the submucosa as a predictor of lymph node involvement in early gastric cancer. World J Surg 1998;22:1056-9.

41. Tsuchiya A, Kikuchi Y, Ando Y, Yoshida T, Abe R. Lymph node metastases in gastric cancer invading the submucosal layer. Eur J Surg Oncol 1995;21:248-50.

42. Yamao T, Shirao K, Ono H, Kondo H, Saito D, Yamaguchi H, et al. Risk factors for lymph node metastasis from intramucosal gastric carcinoma. Cancer 1996;77:602-6.

43. Seto Y, Nagawa H, Muto Y, Kaizaki S, Kitayama J, Muto T. Preliminary report on local resection with lymphadenectopmy for early gastric cancer. Br J Surg 1999;86:526-8.

44. Ohgami M, Otani Y, Kumai K, Kubota T, Kim YI, Kitajima M. Curative laparoscopic surgery for early gastric cancer: 5 years experience. World J Surg 1999;23:187-93.

45. Sano T, Okuyama Y, Kobori O, Shimizu T, Morioka Y. Early gastric cancer: endoscopic diagnosis of depth of invasion. Dig Dis Sci 1990;35:1340-4.

46. Abe S, Lightdale CJ, Brennan MF. The Japanese experience with endoscopic ultrasonography in the staging of gastric cancer. Gastrointest Endosc 1993;39:586-91.
47. Motoo Y, Okai T, Songur Y, Watanabe H, Yamaguchi Y, Mouri I, et al. Endoscopic therapy for early gastric cancer utility of endosonography and evaluation of prognosis. J Clin Gastroenterol 1995;21:17-23.

48. Yanai H, Matsumoto Y, Harada T, Nishiaki M, Tokiyama H, Shigemitsu T, et al. Endoscopic ultrasonography and endoscopy for staging depth of invasion in early gastric cancer: a pilot study. Gastrointest Endosc 1997;46:212-6.

49. Akahoshi K, Chijiiwa Y, Hamada S, Sasaki I, Maruoka A, Kabemura T, et al. Endoscopic ultrasonography: a promising method for assessing the prospects of endoscopic mucosal resection in early gastric cancer. Endoscopy 1997;29:614-9.

50. Ohashi S, Segawa K, Okamura S, Mitake M, Urano H, Shimodaira $\mathrm{M}$, et al. The utility of endoscopic ultrasonography and endoscopy in the endoscopic mucosal resection of early gastric cancer. Gut 1999:45:599-604.

51. Saito N, Takeshita K, Habu H, Endo M. The use of endoscopic ultrasound in determining the depth of cancer invasion in patients with gastric cancer. Surg Endosc 1991;5:14-9.

52. Shimizu S, Tada M, Kawai K. Endoscopic ultrasonography for early gastric cancer. Endoscopy 1994;26:767-8.

53. Yanai H, Tada M, Karita M, Okita K. Diagnostic utility of 20megahertz linear endoscopic ultrasonography in early gastric cancer. Gastrointest Endosc 1996;44:29-33.

54. Kida M, Tanabe S, Watanabe M, Kokutou M, Kondou I, Yamada $\mathrm{Y}$, et al. Staging of gastric cancer with endoscopic ultrasonography and endoscopic mucosal resection. Endoscopy 1998;30(Suppl 1):A64-8.

55. de Aretxabala X, Konishi K, Yonemura Y, Ueno K, Yagi M, Noguchi M, et al. Node dissection in gastric cancer. Br J Surg 1987;74:770-3.

56. Okamura T, Tsujitani S, Korenaga D, Haraguchi M, Baba H, Hiramoto Y, et al. Lymphadenectomy for cure in patients with early gastric cancer and lymph node metastasis. Am J Surg 1988; $155: 476-80$

57. Gunven P, Maruyama K, Okabayashi K, Sasako M, Kinoshita T. Non-ominous micrometastases of gastric cancer. $\mathrm{Br} \mathrm{J}$ Surg 1991;78:352-4.

58. Keller E, Stutzer H, Heitmann K, Bauer P, Gebbensleben B, Rohde H. Lymph node staging in 872 patients with carcinoma of the stomach and the presumed benefit of lymphadenectomy. German Stomach Cancer TNM Study Group. J Am Coll Surg 1994;178:38-46.

59. Seto $\mathrm{Y}$, Nagawa $\mathrm{H}$, Muto T. Intra-operative diagnosis of $\mathrm{N} 2$ lymph node metastasis of gastric cancer. Hepatogastroenterology 1997;44:838-41. 